Supporting Information:

\title{
Manipulation of Ion Types via Gas-Phase Ion/Ion Chemistry for the Structural Characterization of the Glycan Moiety on
}

\section{Gangliosides}

\author{
Hsi-Chun Chao and Scott A. McLuckey* \\ Department of Chemistry \\ Purdue University \\ 560 Oval Drive \\ West Lafayette, Indiana 47907, United States
}

*Address correspondence to:

Dr. Scott A. McLuckey

560 Oval Drive

Department of Chemistry

Purdue University

West Lafayette, IN 47907-2084, USA

Phone: (765) 494-5270

Fax: (765) 494-0239

E-mail: mcluckey@purdue.edu 
Table of Contents

List of Abbreviations

Page S3 - S4

Supporting Experiment Results and Discussion GM1 analysis

.Page S5

Supplementary Figures

.Page S6 - 16

Figure S1. The CID spectra of various ion types of GM1 C36:1

.Page S6

Figure S2. The post-ion/ion reaction spectra of GM3 C40:1 reacting with $\left[\mathrm{Mg}\left(\mathrm{Terpy}_{2}\right)\right]^{2+}$

.Page 57

Figure S2. The $\mathrm{MS}^{4}$ spectrum of fragment ions from [GM3 C40:1+Mg] $]^{+}$ Page S8

Figure S4. The structures of GD1 C36:1 and the proposed fragmentations .Page S9

Figure S5. The MS spectra of GD1 C36:1 ..Page S10

Figure S6. The CID spectra of sodium transfer GD1 C36:1 anions. .Page S11

Figure S7. The structures of GT1b C36:1 and the proposed fragmentations .Page S11

Figure S8. The CID spectra of different ion types of GT1b C36:1 anions Page S12

Figure S9. The structure of Fuc-GM1 C36:1 and CID spectrum of [Fuc-GM1 C36:1-H+Mg] Page S13

Figure S10. The CID spectra of the profiled GD1 C36:1 and Fuc-GD1 38:1 ganglioside from porcine brain .Page S14

Figure S11. The profiled GT1 C36:1 ganglioside from porcine brain Page S15

Figure S12. The profiled Gc-GT1 C36:2 ganglioside from porcine brain.......... .Page S16

Table S1. Profiled gangliosides results Page S17 - S18

Supplementary experimental procedures and results for relative quantification of isomeric GD1 pairs. .Page S19

Reference Page S20 


\section{List of Abbreviations}

GM Gangliosides with a single (mono) sialic acid

GM3

GM1

Fuc-GM1

GD Gangliosides with two (di) sialic acids

GD1a/b

Fuc-GDla/b

GT Gangliosides with three (tri) sialic acids

GT1a/b/c

Fuc-GT1a/b/c

CID Collisional induced dissociation

Terpy 2,2';6',2"-terpyridine

MS Mass spectrometry

CNS Central nervous system

NeuAc N-acetylneuraminic acid

MALDI Matrix assisted laser desorption ionization

TLC Thin layer chromatography

$\mathrm{MS}^{\mathrm{n}} \quad$ Tandem mass spectrometry

ESI Electrospray ionization

LC Liquid chromatography

RP Reversed phase

HILIC Hydrophilic interaction liquid chromatography

RPLC Reversed phase liquid chromatography

2D Two-dimensional

SFC Superficial fluid chromatography

IMS Ion mobility mass spectrometry

HR-IMS High resolution ion mobility mass spectrometry 
SLIM Structures for lossless ion manipulations

UVPD Ultraviolet photo-dissociation

EID electron-induced dissociation

Glc Glucose

Gal Galactose

Fuc Fucose or fucosylated

NeuGc N-Glycolylneuraminic acid

GalNAc N-Acetylgalactosamine

Gc- $\quad$ N-glycolylneuraminic acid $(\mathrm{NeuGc})$ conjugated

PrS Proton Sponge, N, N, N', N'-tetramethyl-1,8-naphthalenediamine 


\section{GM1 analysis}

The same strategy as GM3 analysis is applied for GM1 analysis. Figure S1a shows the CID spectrum of the isolated ion population ([GM1 C36:1-H] $]^{-}, m / z$ 1544.9) with the insert showing the presence of a doubly-charged interferent. The CID spectrum shows some product ions (transparent blue boxes in Figure S1a) from the isolated ion population that could not be rationalized on the basis of the GM1 structure and presumably arise from the doubly-charged interfering species. Figure S1b shows the CID spectrum of the charge-inverted complex cation, [GM1 C36:1-H+MgTerpy] ${ }^{+}(m / z$ 1801.9), and Figure S1c shows CID spectrum of [GM1 $\mathrm{C} 36: 1-\mathrm{H}+\mathrm{Mg}]^{+}(m / z$ 1568.9). As with the GM1 system described above, loss of the remaining Terpy ligand dominates Figure S1c. Figure S1c shows three dominant fragment ions, including water loss, $\mathrm{Y}_{2 \alpha}{ }^{\star}$ (-[Gal-GalNAc], NL of 365), and $\mathrm{Y}_{2 \beta}{ }^{\star}(-[\mathrm{NeuAc}], \mathrm{NL}$ of 291) without the low level unidentified products apparent in Figure S1a 

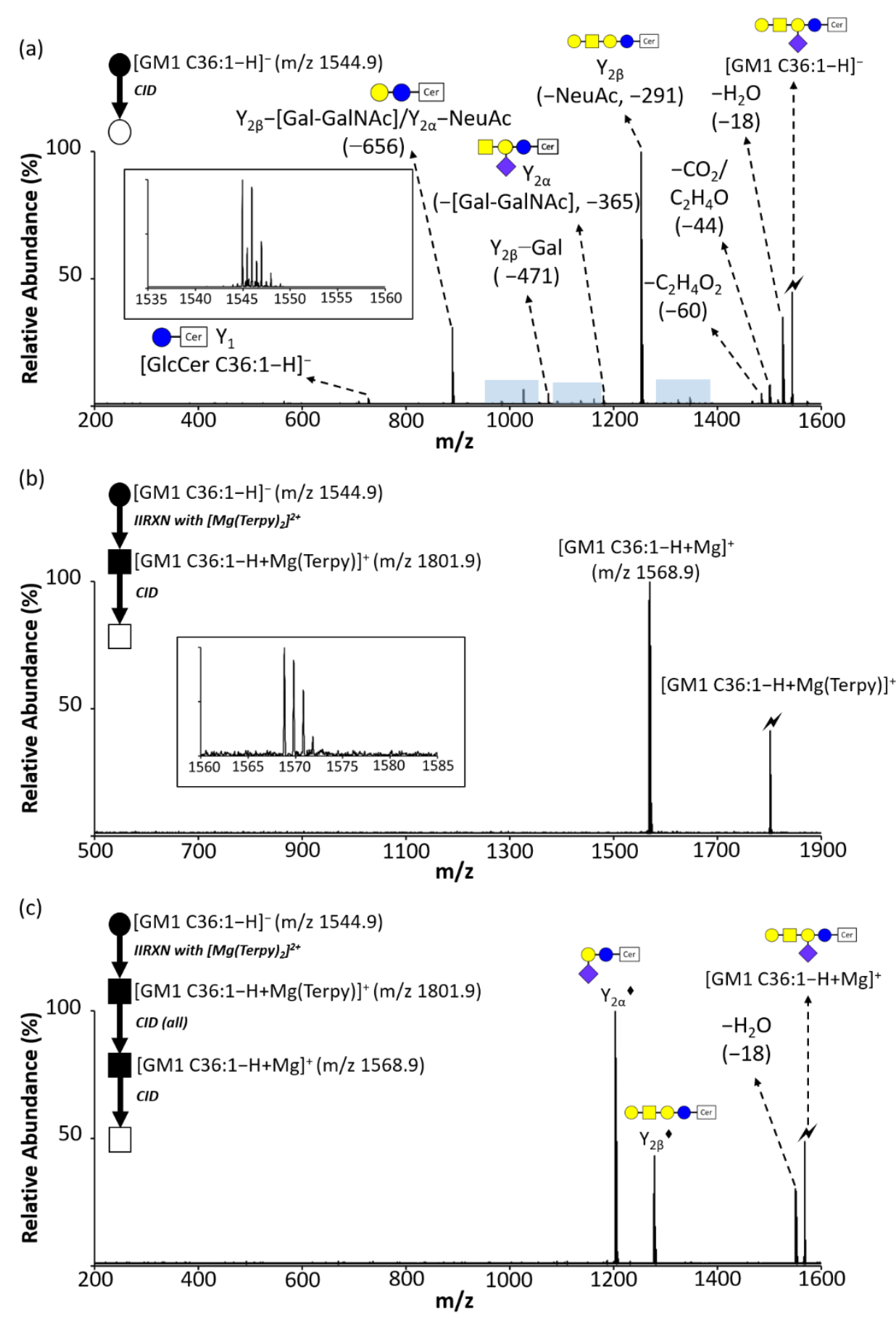

Figure S1. The CID spectra of various ion types of GM1 C36:1. (a) The CID spectrum of $[\text { GM1 C36:1-H] }]^{-}$. (b) The CID spectrum of [GM1 C36:1-H+MgTerpy $]^{+}$. (c) The CID spectrum of [GM1 C36:1-H+Mg] . The insert in (a) is the zoom-in spectrum $(\mathrm{m} / \mathrm{z} 1535$ to 1560 ) for the isolated ion population for [GM1-C36:1-H] $]^{-}$, and the insert in (b) is the zoom-in spectrum $(\mathrm{m} / \mathrm{z} 1560$ to 1585$)$ for the isolated ion population the [GM1 C36:1-H+Mg] ${ }^{+}$. The glycan moiety symbols are consistent with those of Figure 1. The transparent blue boxes highlight the unknown fragment ions. The values inside the parenthesis indicate the neutral loss. The symbols represent as same as those in Figure 2. 


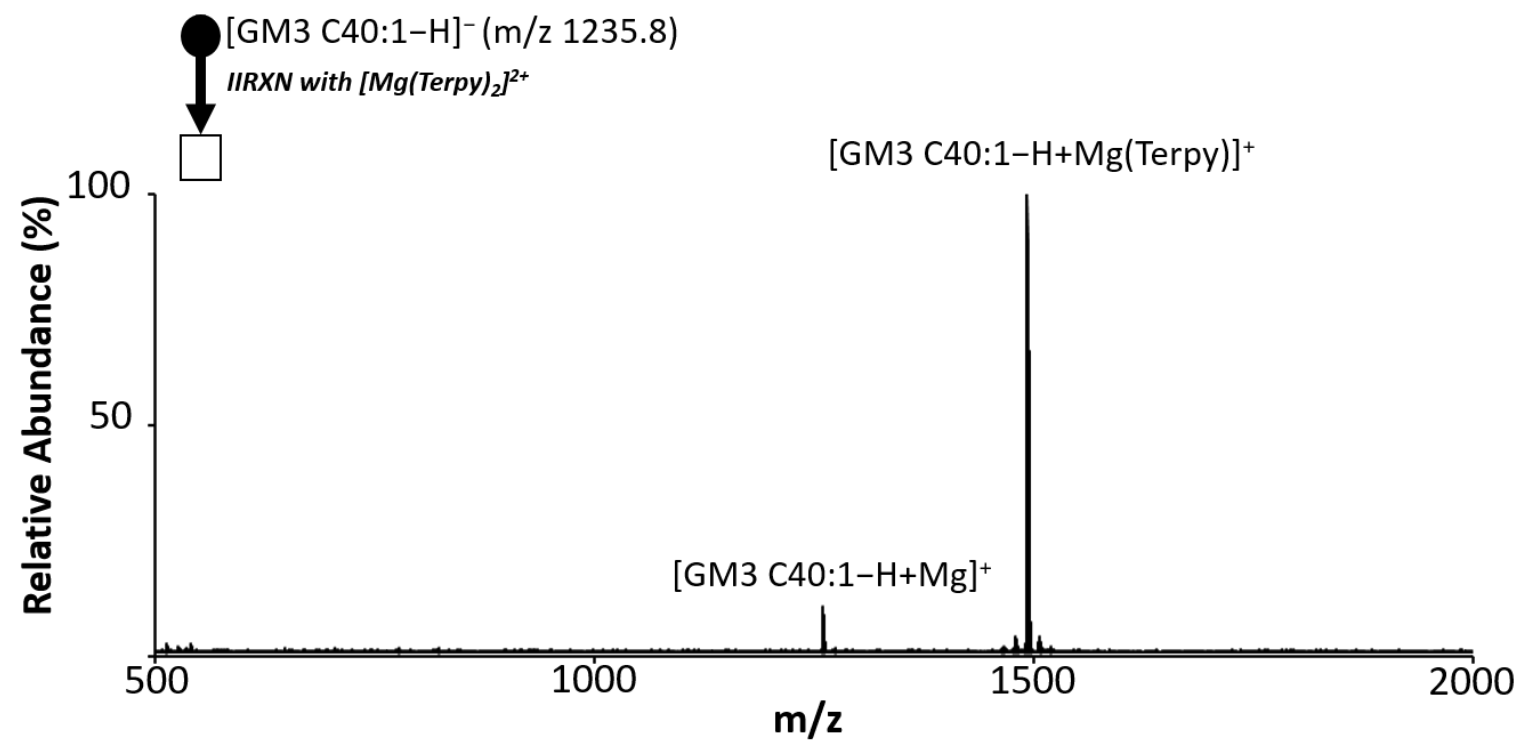

Figure S2. The post-ion/ion reaction spectrum of GM3 C40:1 reacting with $\left[\mathrm{Mg}(\mathrm{Terpy})_{2}\right]^{2+}$. 

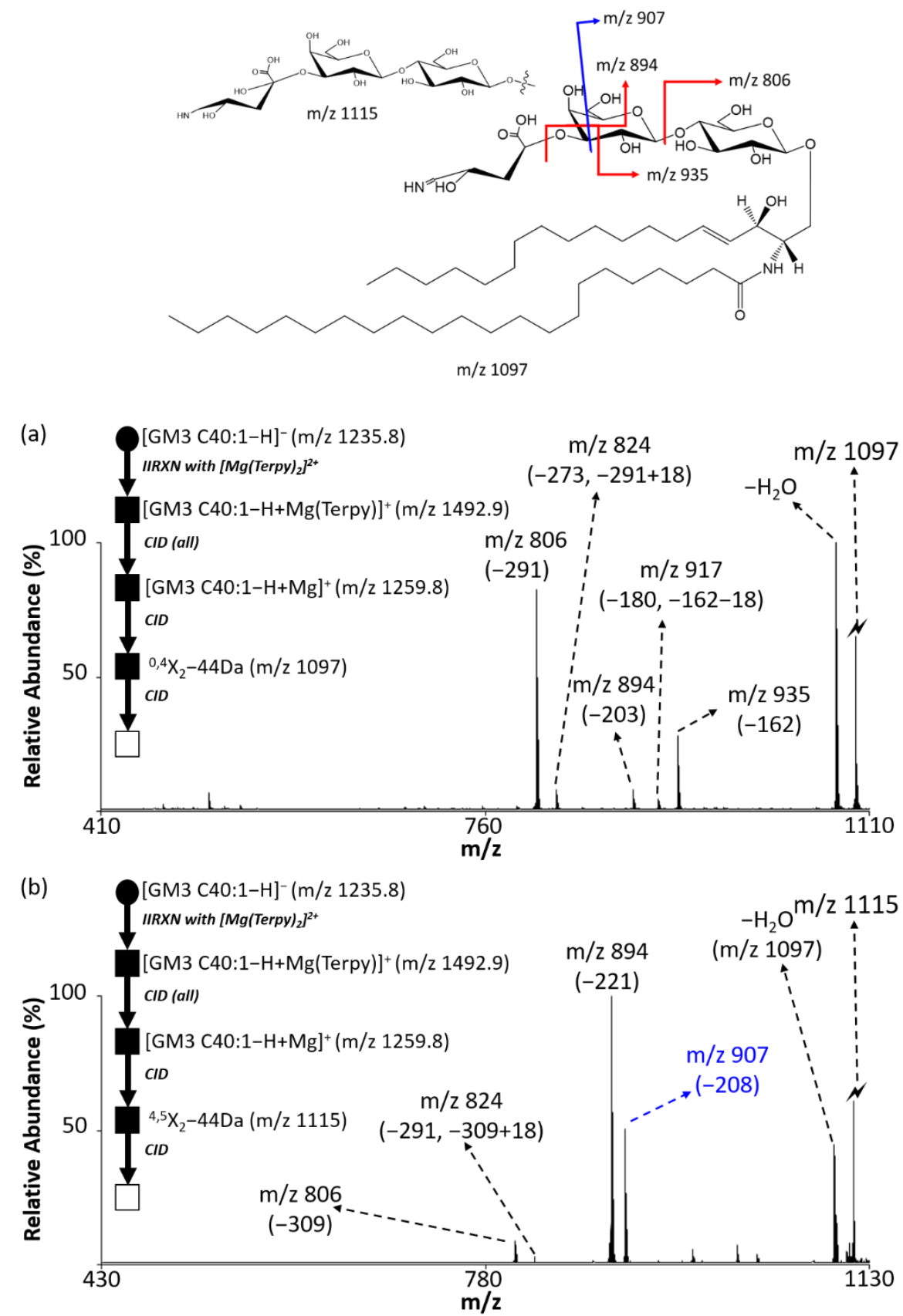

Figure S3. The $\mathrm{MS}^{4}$ spectrum of fragment ions from [GM3 C40:1+Mg] ${ }^{+}$. (a) The CID spectrum from $m / z 1097$ ion. (b) The CID spectrum from $m / z 1115$ ion. The top structure shows the proposed ${ }^{0,4} \mathrm{X}_{2}$ ion and the product ions structures observed in both (a) and (b). The values inside the parenthesis indicate the neutral loss. The lightning bolt signifies the collisionally activated precursor ion. The black ( $)$ indicate the negative ion mode analysis with mass selection. The black and white squares $(\square / \square)$ indicate the positive ion mode analysis with and without mass selection, respectively. All ions are with $\mathrm{Mg}^{2+}$ adduction. 
(a) GD1a C36:1

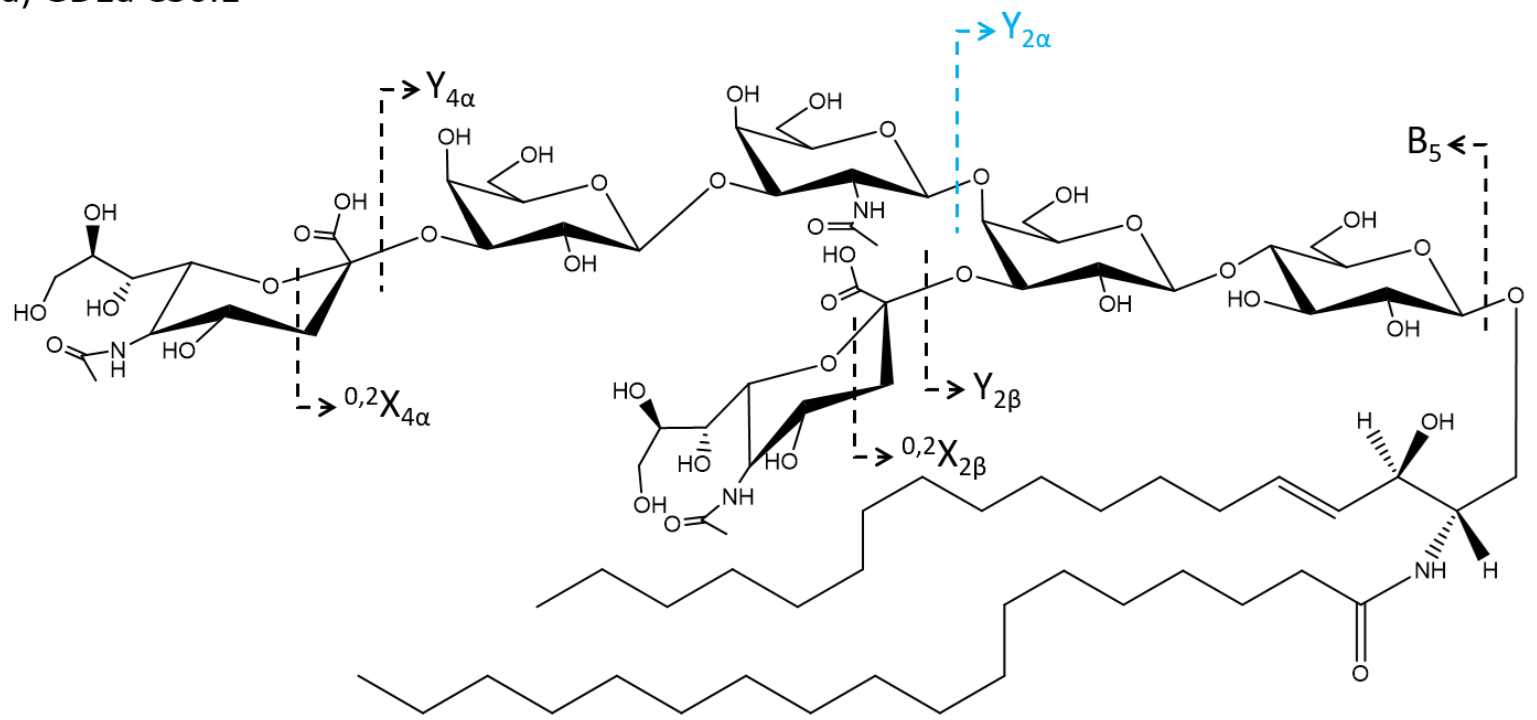

(b) GD1b C36:1

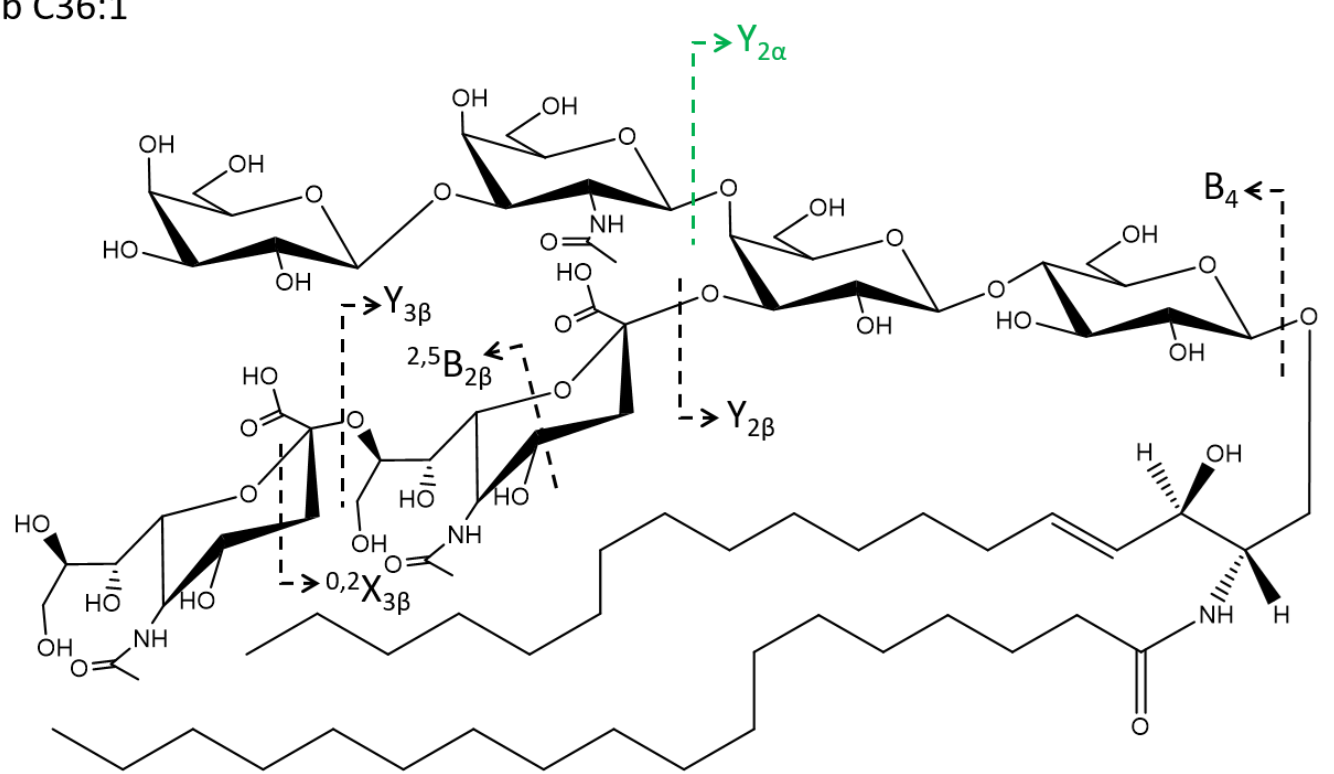

Figure S4. The structures of GD1-C36:1 and the proposed fragmentations. (a) GD1a-C36:1. (b) GD1b-C36:1. 

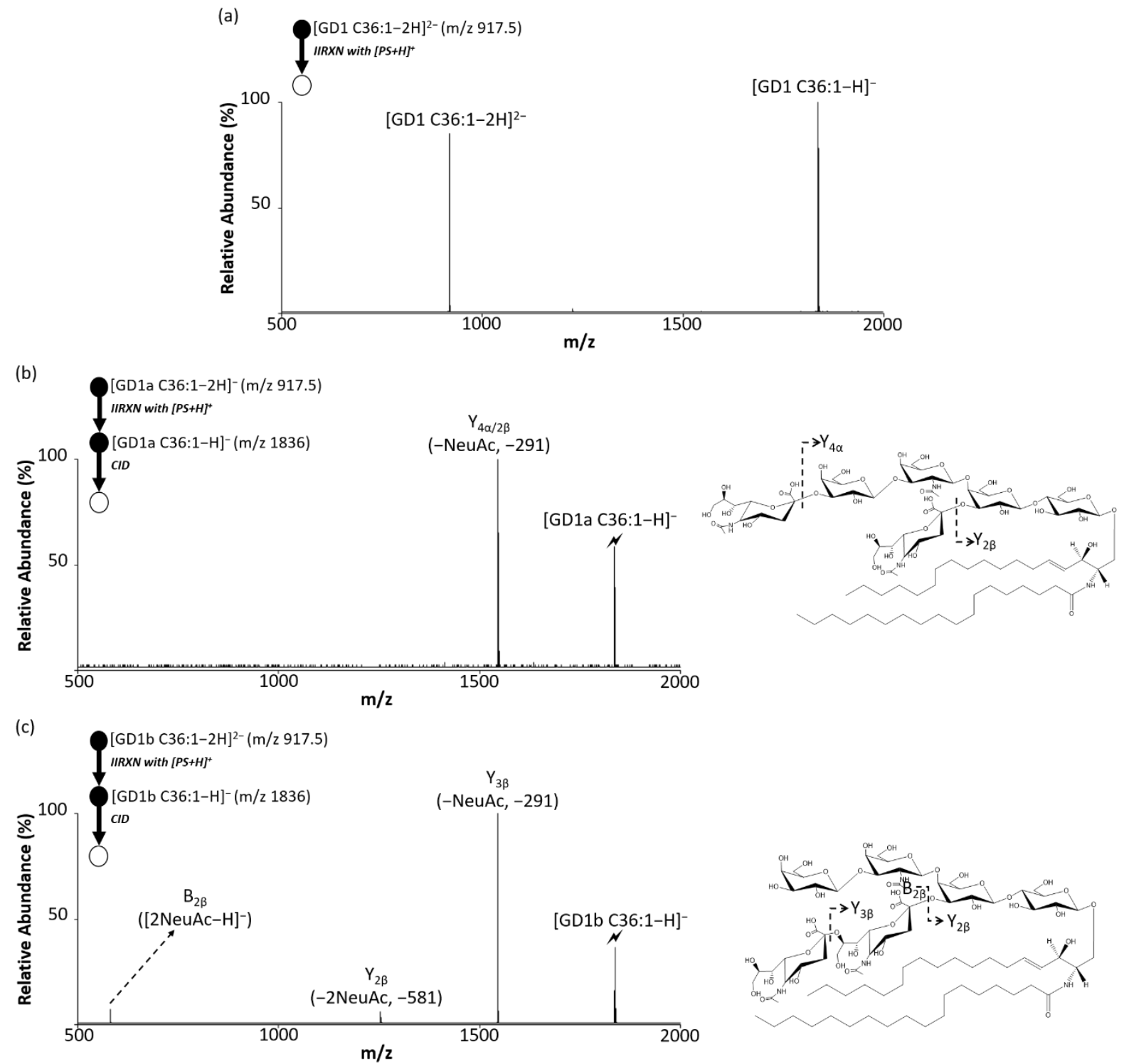

Figure S5. The MS spectra of GD1 C36:1. (a) The post-proton transfer reaction mass spectrum between [GD1 C36:1-2H $]^{2-}$ and proton sponge $\left([\mathrm{PrS}+\mathrm{H}]^{+}\right)$. (b) The CID spectrum of [GD1a $\mathrm{C} 36: 1-\mathrm{H}]^{-}$with the structure. (c) The CID spectrum of [GD1b C36:1-H $]^{-}$with the structure. The lightning bolt signifies the collisionally activated precursor ion. The black and white circle $(\mathbf{O})$ indicate the negative ion mode analysis with or without mass selection. 


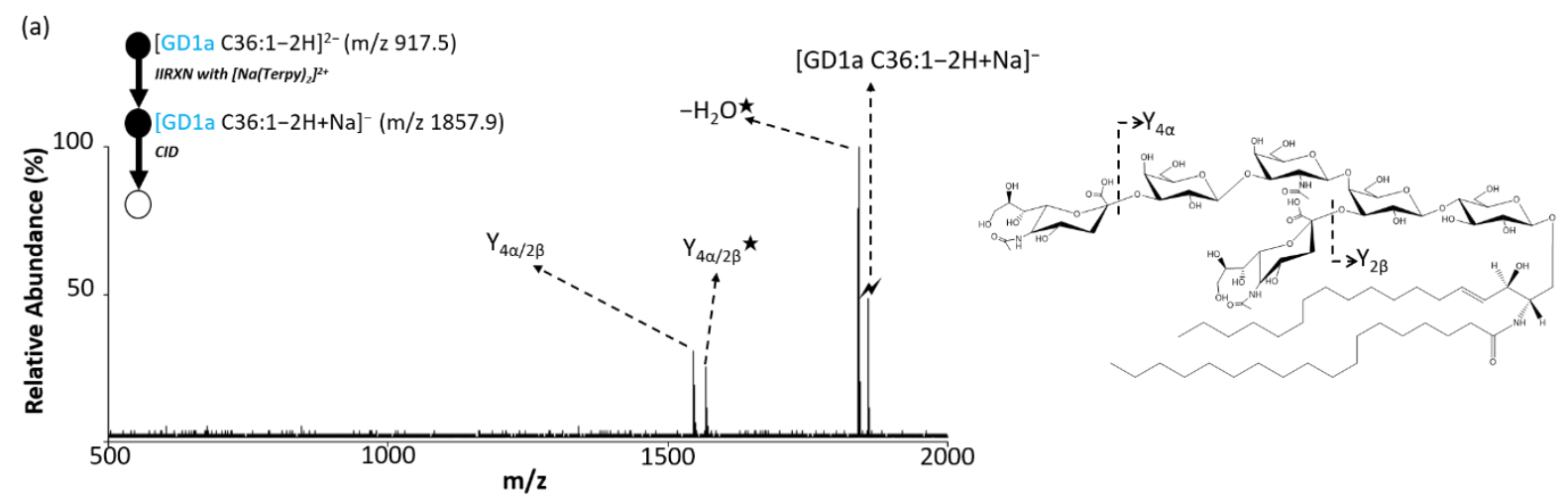

(b)

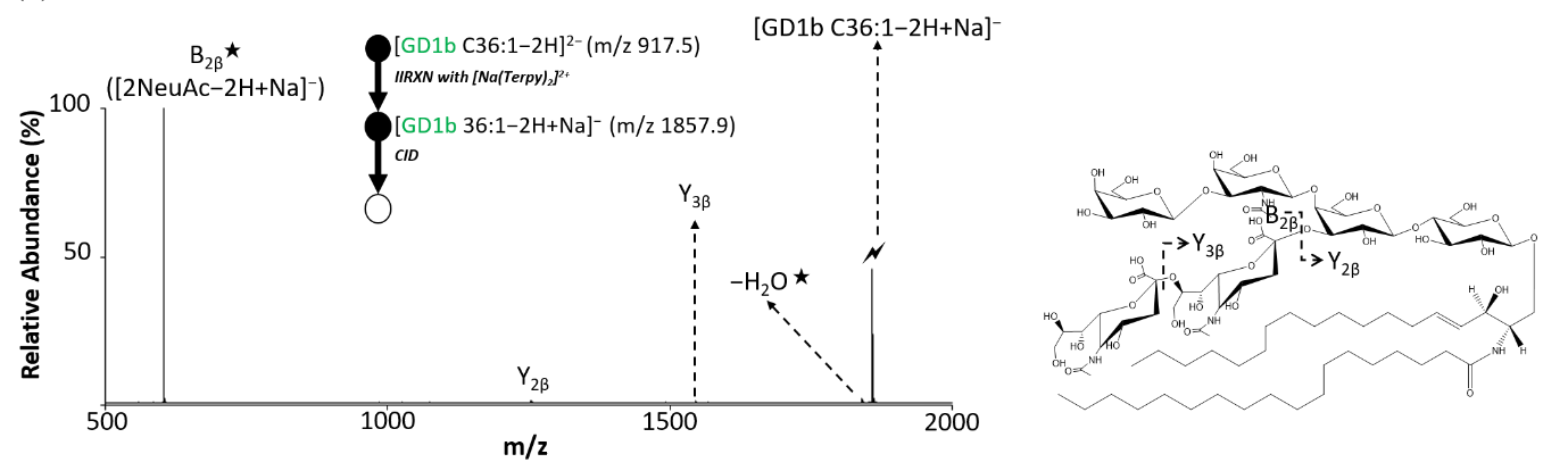

Figure S6. The CID spectra of sodium transfer GD1 C36:1 anions. (a) The CID spectrum of [GD1a C36:1-2H+Na] $]^{-}$with the structure. (b) The CID spectrum of [GD1b C36:1-2H+Na] with the structure. The lightning bolt signifies the collisionally activated precursor ion. The black and white circle $(\mathbf{O} / \mathrm{O})$ indicate the negative ion mode analysis with or without mass selection. The $\star$ indicates the ion with sodium $\left(\mathrm{Na}^{+}\right)$.

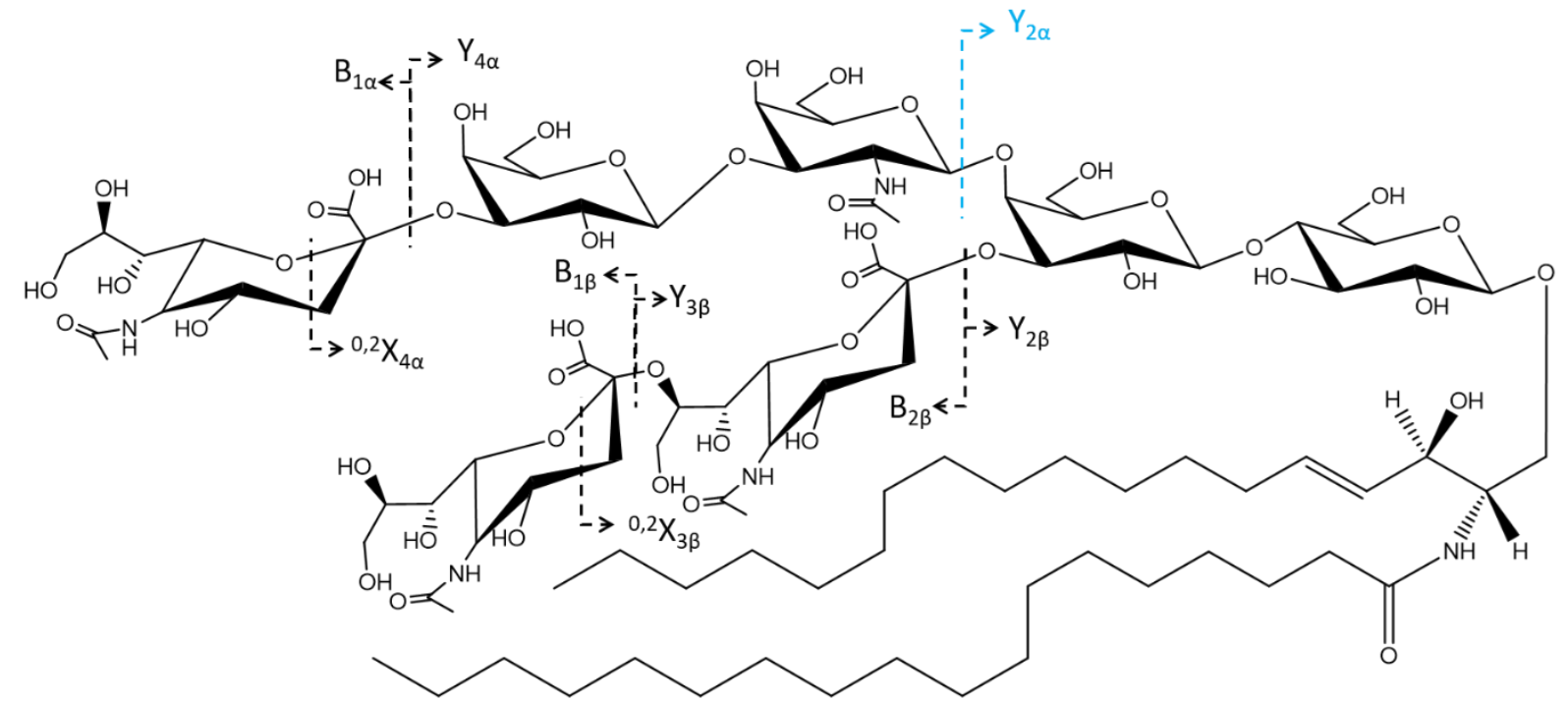

Figure S7. The structures of GT1b C36:1 and the proposed fragmentations. 

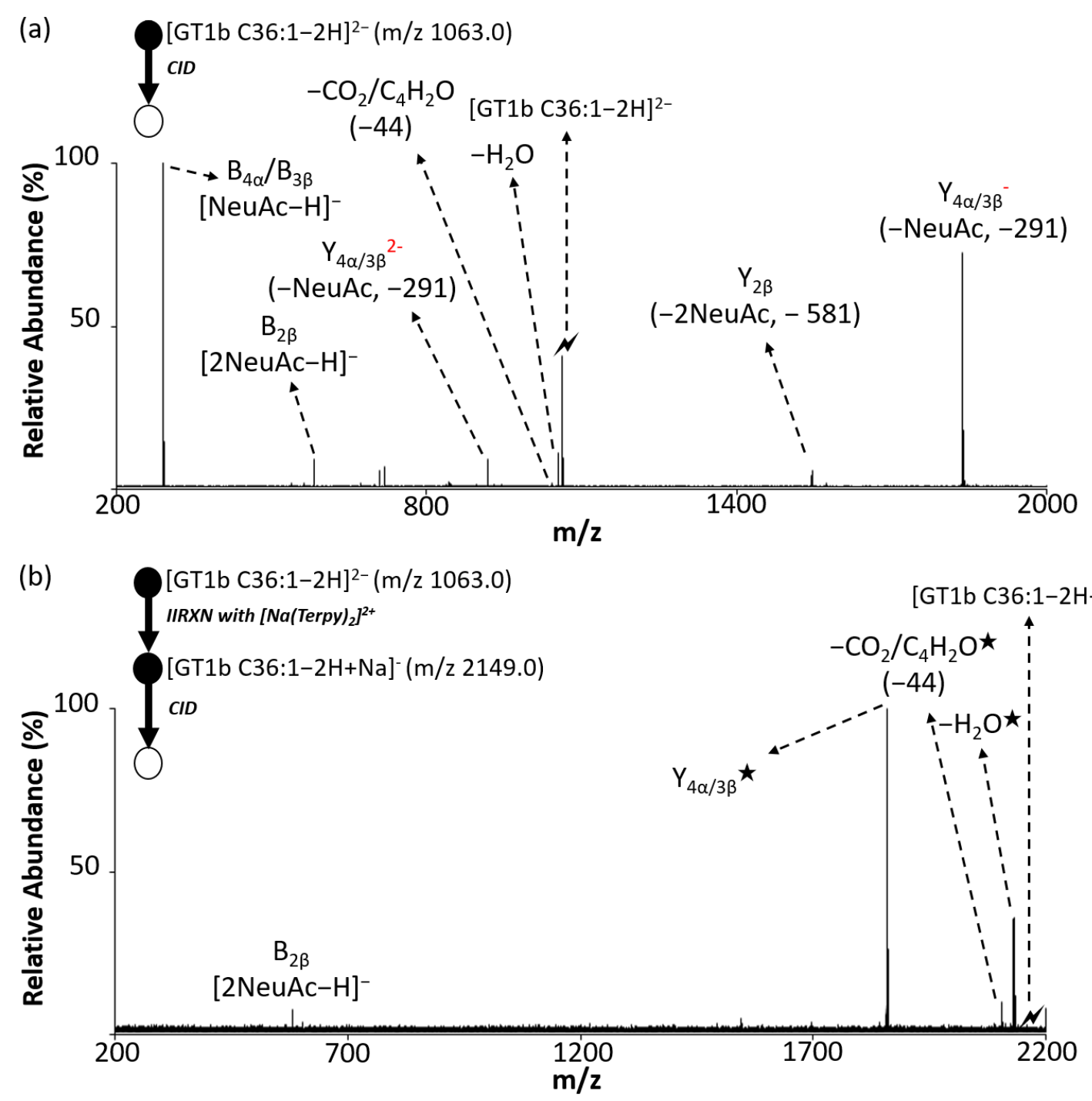

Figure S8. The CID spectra of different ion types of GT1b C36:1 anions. (a) The CID spectrum of [GT1b C36:1-2H $]^{2-}$. (b) The CID spectrum of [GT1b C36:1-2H+Na] $]^{-}$The lightning bolt signifies the collisionally activated precursor ion. The black and white circle $(\odot / O)$ indicate the negative ion mode analysis with or without mass selection. The $\star$ indicates the ion with sodium $\left(\mathrm{Na}^{+}\right)$. The structures of the fragment ions are shown in Figure S6. 


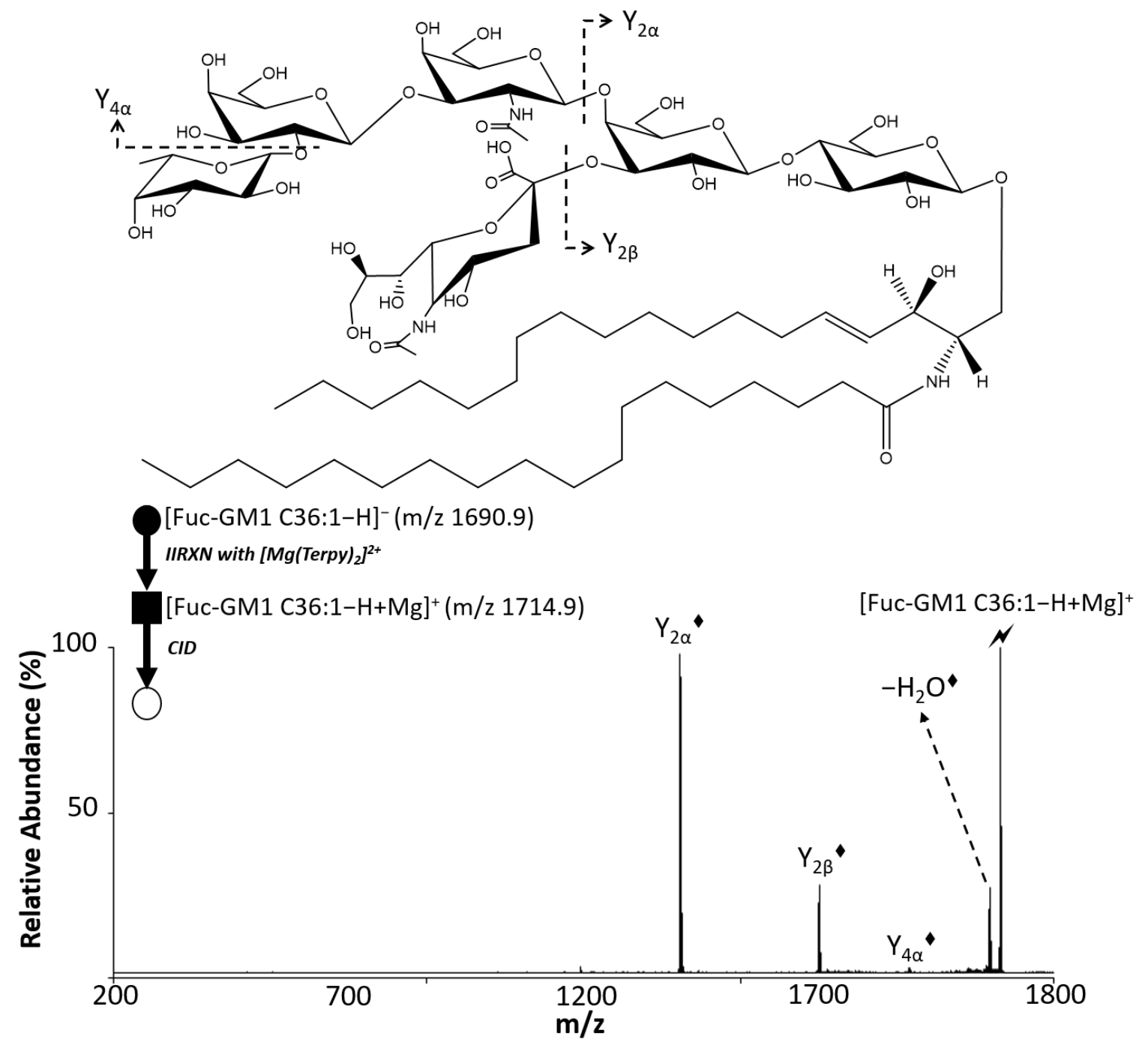

Figure S9. The structure of Fuc-GM1 C36:1 and CID spectrum of [Fuc-GM1 C36:1-H+Mg] $]^{+}$ The lightning bolt signifies the collisionally activated precursor ion. The black and white circle $(\mathbf{O})$ indicate the negative ion mode analysis with and without mass selection, respectively. The black and white squares $(\square / \square)$ indicate the positive ion mode analysis with and without mass selection, respectively. The diamond ( $\bullet$ indicates the ion with $\mathrm{Mg}^{2+}$. 


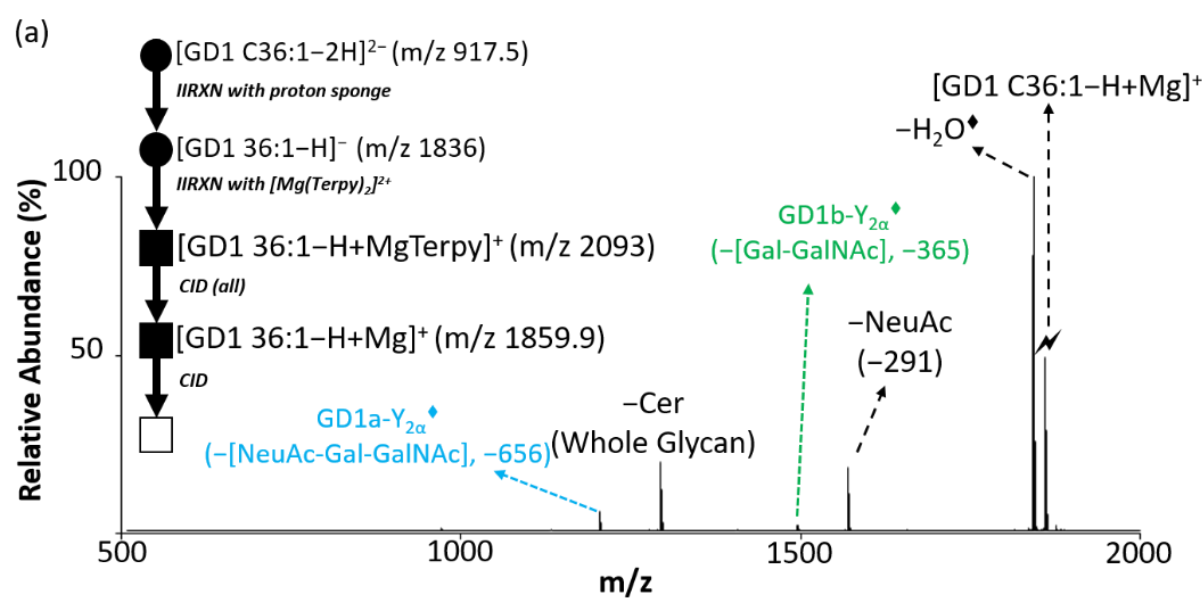

(b)

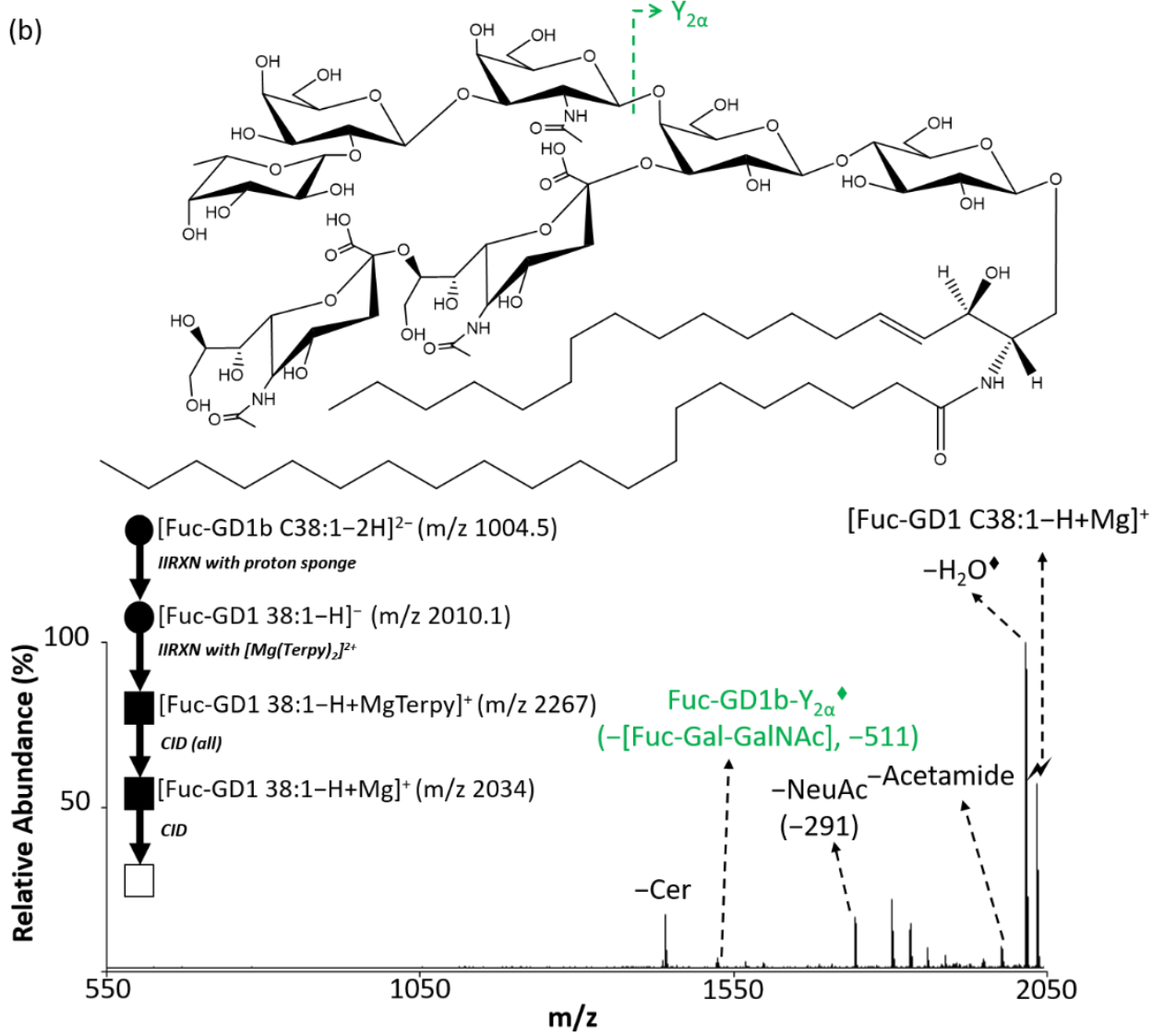

Figure S10. The CID spectra of the profiled GD1 C36:1 and Fuc-GD1 38:1 gangliosides from porcine brain. (a) The CID spectrum of [GD1 C36:1-H+Mg] $]^{+}(\mathrm{m} / \mathrm{z} 1859.9)$, and the structures of the fragment ions could be found in Figure S6. (b) The CID spectrum of [Fuc-GD1 $\mathrm{C} 38: 1-\mathrm{H}+\mathrm{Mg}]^{+}(\mathrm{m} / \mathrm{z} 2034)$ and the structure. The lightning bolt signifies the collisionally activated precursor ion. The black and white circle $(\mathbf{O} /)$ indicate the negative ion mode analysis with and without mass selection, respectively. The black and white squares $(\square / \square)$ indicate the positive ion mode analysis with and without mass selection, respectively. The diamond ( $\bullet$ indicates the ion with $\mathrm{Mg}^{2+}$. 
(a) GT1a C36:1

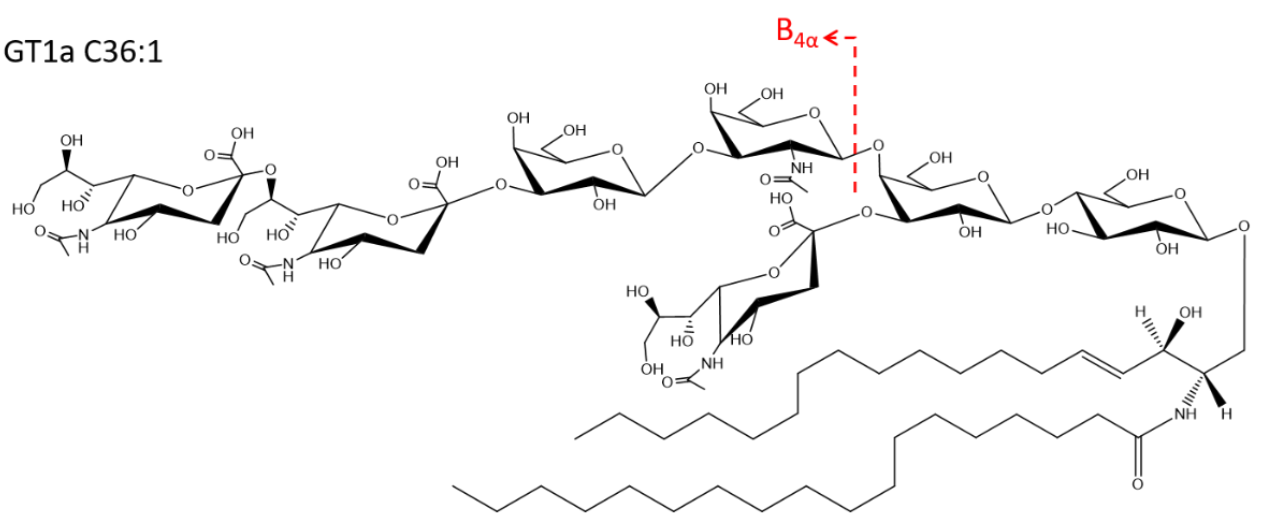

(a) GT1c C36:1

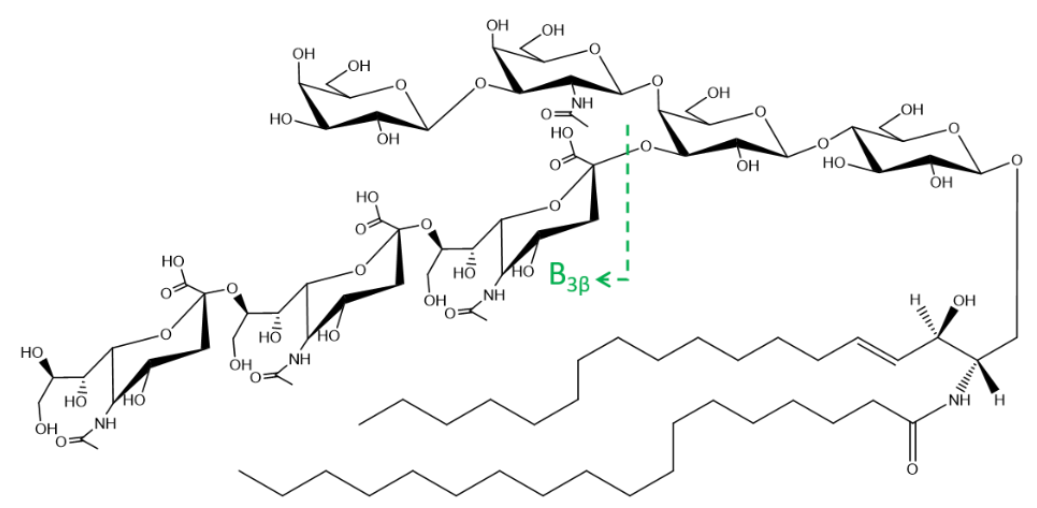

(c) GT1 C36:1 Spectrum

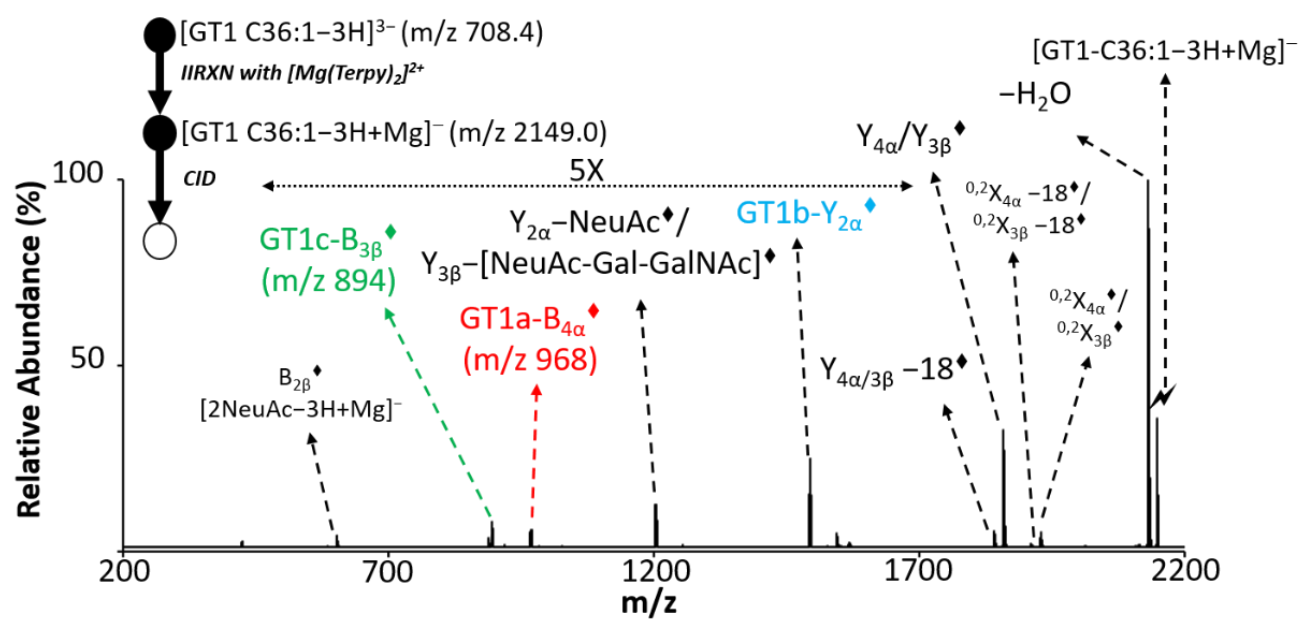

Figure S11. The profiled GT1 C36:1 gangliosides from porcine brain. (a) The structure of GT1a-C36:1 and the diagnostic ion. (b) The structure of GT1c C36:1 and the diagnostic ion. (c) The CID spectrum of the profiled [GT1 C36:1-3H+Mg] from porcine brain. The labels in black are the labels from GT1b structure (Figure S6). The black and white circle $(\mathbf{O} /)^{\prime}$ indicate the negative ion mode analysis with or without mass selection. The $\bullet$ indicates the ion with $\mathrm{Mg}^{2+}$. 


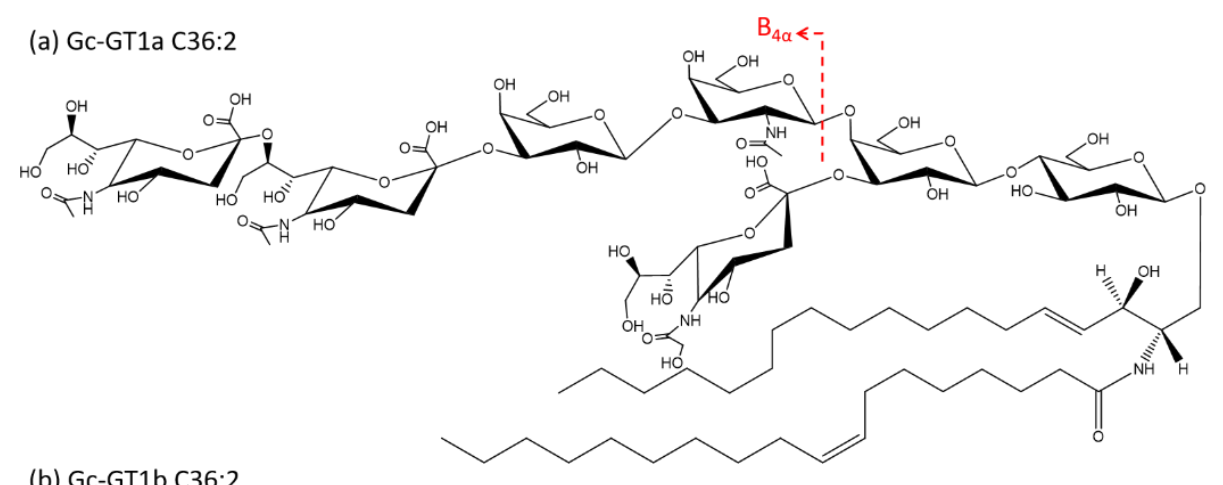

(c) Gc-GT1c C36:2

(b) Gc-GT1b C36:2

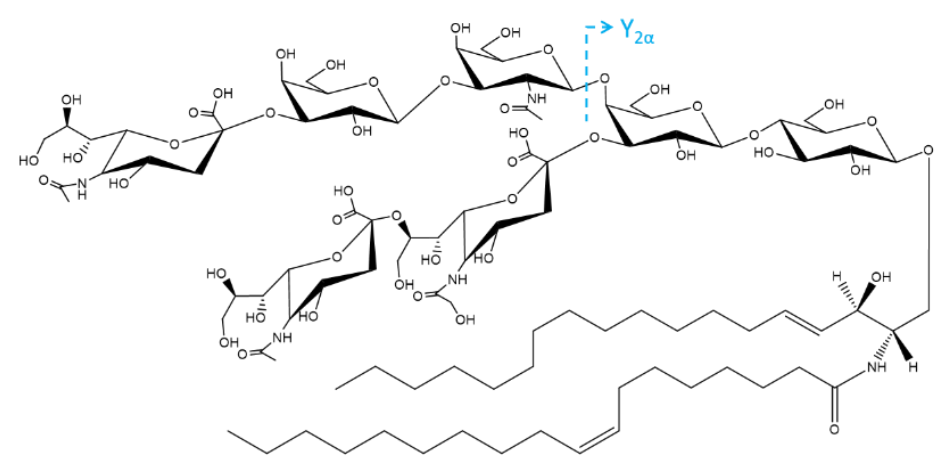

(d) Gc-GT1 C36:2 Spectrum

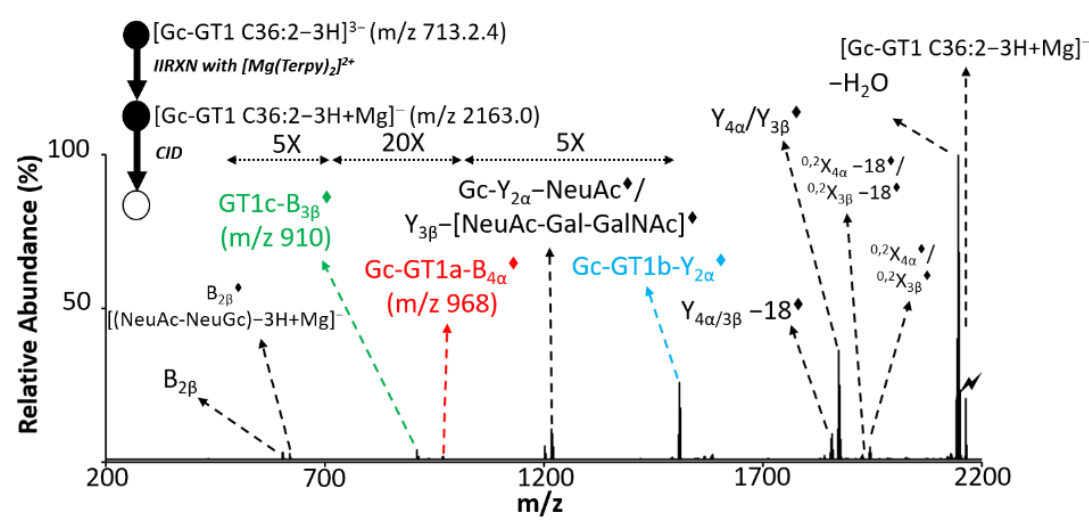

Figure S12. The profiled Gc-GT1 C36:2 gangliosides from porcine brain. (a) The structure of Gc-GT1a C36:2 and the diagnostic ion. (b) The structure of Gc-GT1b C36:2 and the diagnostic ion. (c) The structure of Gc-GT1b C36:2 and the diagnostic ion. (d) The CID spectrum of the profiled [Gc-GT1 C36:2-3H+Mg] from porcine brain. The labels in black are the labels from GT1b structure (Figure S7). The black and white circle $(\mathbf{O})$ indicate the negative ion mode analysis with or without mass selection. The $\bullet$ indicates the ion with $\mathrm{Mg}^{2+}$. Noted that the double bond on the amide-bonded fatty acyl chain only indicates the monounsaturated fatty acyl side chain is in the structure but not the real unsaturation site. 
Table S1. Profiled gangliosides from porcine brain using the proposed workflow.

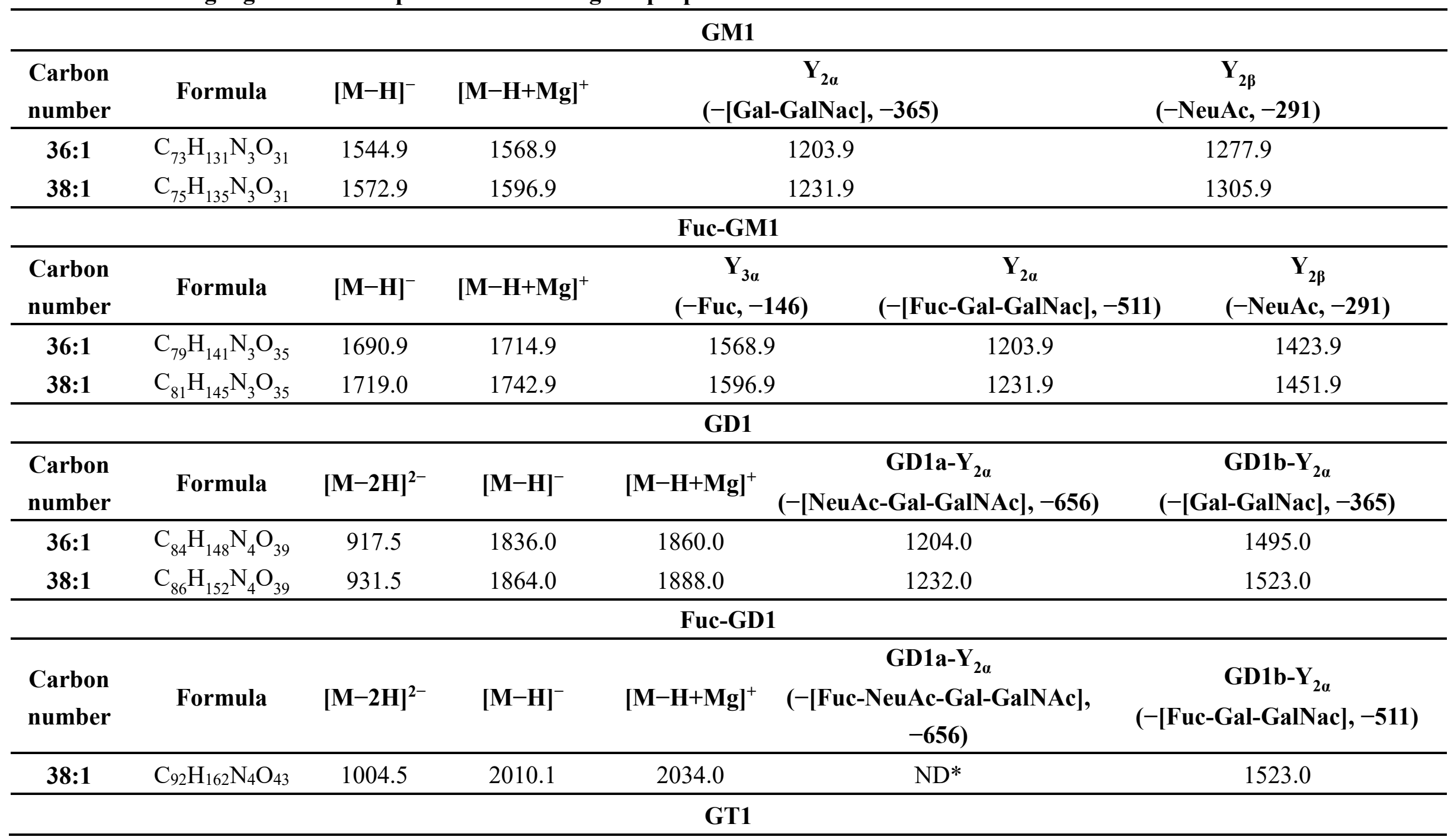




\begin{tabular}{|c|c|c|c|c|c|c|}
\hline $\begin{array}{l}\text { Carbon } \\
\text { number }\end{array}$ & Formula & {$[\mathbf{M}-3 \mathbf{H}]^{3-}$} & {$[\mathbf{M}-\mathbf{3 H}+\mathbf{M g}]^{-}$} & $\begin{array}{c}\text { GT1a-B4a } \\
([2 \mathrm{NeuAc}-\mathrm{Gal}- \\
\text { GalNAc-3H+Mg] } \\
\end{array}$ & $\begin{array}{c}\text { GT1b-Y2 } \alpha \\
\text { (-[NeuAc-Gal-GalNAc], } \\
-656) \\
\end{array}$ & $\begin{array}{c}\text { GT1c-B } 3 \beta \\
\left(\left[3 \mathrm{NeuAc}-3 \mathrm{H}+\mathrm{Mg}^{-}\right)\right.\end{array}$ \\
\hline $34: 1$ & $\mathrm{C}_{93} \mathrm{H}_{161} \mathrm{~N}_{5} \mathrm{O}_{47}$ & 699.0 & 2121.0 & ND & 1465.0 & 894.2 \\
\hline $36: 1$ & $\mathrm{C}_{95} \mathrm{H}_{165} \mathrm{~N}_{5} \mathrm{O}_{47}$ & 708.4 & 2149.0 & 968.3 & 1493.0 & 894.2 \\
\hline $36: 2$ & $\mathrm{C}_{95} \mathrm{H}_{163} \mathrm{~N}_{5} \mathrm{O}_{47}$ & 707.7 & 2147.0 & ND & 1491.0 & 894.2 \\
\hline $38: 1$ & $\mathrm{C}_{97} \mathrm{H}_{169} \mathrm{~N}_{5} \mathrm{O}_{47}$ & 717.7 & 2177.0 & 968.3 & 1521.0 & 894.2 \\
\hline 40:1 & $\mathrm{C}_{99} \mathrm{H}_{173} \mathrm{~N}_{5} \mathrm{O}_{47}$ & 727.0 & 2205.1 & ND & 1549.1 & ND \\
\hline 42:1 & $\mathrm{C}_{101} \mathrm{H}_{177} \mathrm{~N}_{5} \mathrm{O}_{47}$ & 736.4 & 2233.1 & ND & 1577.1 & ND \\
\hline $42: 2$ & $\mathrm{C}_{101} \mathrm{H}_{175} \mathrm{~N}_{5} \mathrm{O}_{47}$ & 735.7 & 2231.1 & ND & 1575.1 & 894.2 \\
\hline $44: 1$ & $\mathrm{C}_{103} \mathrm{H}_{181} \mathrm{~N}_{5} \mathrm{O}_{47}$ & 745.7 & 2261.2 & ND & 1605.1 & ND \\
\hline \multicolumn{7}{|c|}{ Gc-GT1 } \\
\hline $\begin{array}{l}\text { Carbon } \\
\text { number }\end{array}$ & Formula & {$[\mathbf{M}-\mathbf{3 H}]^{3-}$} & {$[\mathbf{M}-\mathbf{3 H}+\mathbf{M g}]^{-}$} & $\begin{array}{c}\text { Gc-GT1a-B } 4 a \\
([2 N e u A c-G a l- \\
\left.\text { GalNAc-3H+Mg] }]^{-}\right) \\
\end{array}$ & $\begin{array}{c}\text { Gc-GT1b-Y } 2 a \\
\text { (-[NeuAc-Gal-GalNAc], } \\
-656) \\
\end{array}$ & $\begin{array}{c}\text { Gc-GT1c-B } 3 \beta \\
([\text { NeuGc- } \\
\left.\text { 2NeuAc-3H+Mg] }]^{-}\right) \\
\end{array}$ \\
\hline $36: 1$ & $\mathrm{C}_{95} \mathrm{H}_{165} \mathrm{~N}_{5} \mathrm{O}_{48}$ & 713.7 & 2165.0 & ND & 1509.0 & ND \\
\hline $36: 2$ & $\mathrm{C}_{95} \mathrm{H}_{163} \mathrm{~N}_{5} \mathrm{O}_{48}$ & 713.2 & 2163.0 & 968.3 & 1507.0 & 910.2 \\
\hline $38: 2$ & $\mathrm{C}_{97} \mathrm{H}_{167} \mathrm{~N}_{5} \mathrm{O}_{48}$ & 722.4 & 2191.0 & ND & 1537.0 & 910.2 \\
\hline $40: 2$ & $\mathrm{C}_{99} \mathrm{H}_{171} \mathrm{~N}_{5} \mathrm{O}_{48}$ & 731.7 & 2219.1 & ND & 1563.1 & 910.2 \\
\hline $42: 2$ & $\mathrm{C}_{101} \mathrm{H}_{175} \mathrm{~N}_{5} \mathrm{O}_{48}$ & 741.0 & 2247.1 & 968.3 & 1591.0 & ND \\
\hline
\end{tabular}

*ND: non-detected. 


\section{Supporting Experimental Procedure}

\section{Relative Quantification of Isomeric GD1 in Porcine Brain Sample}

To perform relative quantification of porcine, we first analyzed the pure GD1a or GD1b from the standard mixture. We are able to obtain pure GD1a or GD1b from Q1 mass selection via the instrument. The selected ions were then subjected into $\mathrm{q} 2$ for further reaction and dissociation (details in main text, experimental section) to produce magnesium transfer product cations, $[\mathrm{GD} 1-\mathrm{H}+\mathrm{Mg}]^{+}$. Next, ion-trap CID were performed to fully deplete the precursor cation, $[\mathrm{GD} 1-\mathrm{H}+\mathrm{Mg}]^{+}$, obtaining the CID spectra.

We further extracted the peak areas from the monoisotopic peaks of the major fragment ions and normalized with the total extracted peak area. The normalized results are showed in the following Table S2. Next, the same procedures were performed on the profiled GD gangliosides from the porcine brain sample, and the normalized fragment patterns are also obtained. A total least square strategy is then utilized to match the normalized peak area from the profiled gangliosides from the porcine brain to those corresponding pure component analyses. ${ }^{1}$ We then could obtain the percentages from the both isomers in the isomeric pair to know their relative quantity in the sample. The results are shown in Table S3.

Table S2. The normalized \%area from the extracted fragment ions from pure GD1 isomers.

\section{Normalized \%Area from Each Fragment Ion}

\begin{tabular}{cccccc}
\hline $\begin{array}{c}\text { Carbon } \\
\text { number }\end{array}$ & Water Loss & NeuAc Loss & GD1b-Y $2 \boldsymbol{c}$ & Glycan moiety & GD1a-Y ${ }_{2 \alpha}$ \\
C36:1 & & & & & \\
\hline GD1a & $46.7 \pm 0.4^{*}$ & $35.1 \pm 0.5$ & 0 & $11 \pm 0.1$ & $7.2 \pm 0.1$ \\
GD1b & $74.5 \pm 0.4$ & $15.8 \pm 0.6$ & $3.6 \pm 0.2$ & $6.1 \pm 0.3$ & 0 \\
\hline C38:1 & & & & & \\
\hline GD1a & $51.7 \pm 0.2$ & $26.4 \pm 0.5$ & 0 & $13.6 \pm 0.3$ & $8.3 \pm 0.4$ \\
GD1b & $72.7 \pm 0.7$ & $16.2 \pm 0.2$ & $4.1 \pm 0.1$ & $7.0 \pm 0.4$ & 0 \\
\hline
\end{tabular}

$*$ Mean \pm SD $(n=3)$.

Table S3. The relative quantification (\%) results of the profiled isomeric GD1 in porcine brain.

\begin{tabular}{cccc}
\hline carbon number & GD1a & GD1b & Total \\
\hline $\mathbf{3 6 : 1}$ & $71.7 \pm 2.3^{*}$ & $24.9 \pm 2.1$ & $96.6 \pm 4.4$ \\
$\mathbf{3 8 : 1}$ & $86.2 \pm 2.1$ & $13.0 \pm 2.3$ & $99.2 \pm 4.4$ \\
\hline
\end{tabular}

$*$ Mean \pm SD $(n=3)$. 


\section{Reference:}

1. Randolph, C. E.; Foreman, D. J.; Blanksby, S. J.; McLuckey, S. A., Generating Fatty Acid Profiles in the Gas Phase: Fatty Acid Identification and Relative Quantitation Using Ion/Ion Charge Inversion Chemistry. Anal Chem 2019, 91 (14), 9032-9040. 